\title{
Teaching Statistics With Constructivist- Based Learning Method To Describe Student Attitudes Toward Statistics
}

Yea-Ling Tsao, (Email: tsaojennifer@ hotmail.com), Taipei Municipal University of Education, Taiwan

\begin{abstract}
In this study, the researcher examined the effect of a semester-long, constructivist-based learning approach method on student attitudes toward statistics in an introductory statistics course. The author investigated whether students who engaged in constructivist-based learning environment performed more positive attitudes toward statistics. Results showed that, the constructivist-based learning approach technique encouraged students to become more positive attitudes toward statistics with the course content through active-learning environment. Thus, these findings have important implications for course content and instructional delivery.
\end{abstract}

\section{INTRODUCTION}

tatistics has impacted the curriculum in all level education fields. In almost every discipline, the ability to understand, interpret, and critically evaluate research findings are becoming an essential core skill (Giesbrecht, 1996). Because of this growing movement to expand and include statistics into all levels of education, there is also considerable interest in student attitudes toward statistics. Student attitudes toward statistics have been reported as negative and if so, can influence the learning process and becomes a major obstacle to effective learning (Schutz, Drogsz, White, \& Distefano, 1998). Furthermore, attitudes and beliefs about statistics may affect the extent to which students will develop useful statistical thinking skills, whether they will apply what they have learned outside of the classroom, and whether or not students will choose to enroll in further statistics courses (Gal, Ginsburg, \& Schau, 1997). Most importantly, student attitudes deserve attention because they can influence the teaching/learning process.

In recent years many statisticians have become involved in the reform movement in statistical education aimed at the teaching of introductory statistics. Moore (1997) describes the reform in terms of changes in content (more data analysis, less probability), pedagogy (fewer lectures, more active learning), and technology (for data analysis and simulations). Garfield (1995) offered a research perspective on why and how teaching methods should be changed, and many statisticians have suggested ways to incorporate technology into the introductory course (Velleman and Moore 1996). The other argument for reform is that students learn better and retain more if they engage in learning activities that require them to think and process information rather than passively listen to lectures. Hogg (1991) suggested that using cooperative learning techniques would promote active learning.

\section{LITERATURE REVIEW}

The traditional format used by college and university educators promotes passive learning: Students are required to merely listen to and take notes on a lecture, without participating in the lecture material (Dabbour, 1997). Despite the prevalence of the lecture format, Shakarian (1995) suggested that passive learning techniques are limited in their ability to facilitate students' learning because they do not encourage students to process information actively. In contrast, active learning techniques require students to apply theory to real-life situations in a dynamic manner (Lewis \& Williams, 1994) and engage students in higher order thinking as they personalize the subject matter 
(Anderson, 1997). Experiential learning as a formal part of college and university curricula could infuse learning activities into courses and programs to make those activities more relevant for all students. Active learning experiences can provide the increasingly growing numbers of nontraditional learners as well as traditional learners with valuable opportunities to apply theory to practice.

Cobb (1993) stated the advantages of hands-on activities in which students are actively involved in data production. Because the data are "fresh, not someone's leftovers" (p. 7), the students are nearly always motivated to analyze the data. As Fillebrown (1994), reported similar interest and motivation among her students when they collected their own data. On a questionnaire administered at the end of the quarter, student comments regarding the projects were positive. As one of her students stated, " The project was interesting because it was a topic of our choice" (Fillebrown, 1994, p. 7). Bradstreet (1996) found that students who are actively involved in defining problems and analyzing data have "emotional stakes in learning the statistical material necessary to solve their real world problem" (p.75). Gordon (1995) reported a feeling of achievement as one consequence for adult students of statistics. Not only did the students express a sense of accomplishment in the study of statistics, they increased their selfconfidence.

Vellerman and Moore (1996) stated that modern introduction to statistics should begin with the tools and strategies necessary for exploration and understanding of data. We should ask students to analyze real data as a means of both reinforcing and assessing the learning of new concepts and skills and as a basis for motivating the concerns of inferences.

\section{DESIGN OF CONSTRUCTIVIST-BASED LEARNING METHOD}

A major goal of an introductory statistics class is to teach students to think critically, using the fundamental concepts of statistics. Students should be able to organize and summarize data, draw inferences from such summaries, and incorporate such summaries and inferences into reports. Constructivist-based learning techniques promote learning through small group work experiences and involvement in learning activities other than just listening. These can include projects that require class participation through hands-on experiments or demonstrations that illustrate lecture material. For the undergraduate students of statistics, this participation can be in the form of projects involving sampling, data analysis, and experimental design. The researcher proctored the administration of the instrument according to a standard procedure.

The class sessions were one-and-half hours in length which allowed the researcher and the students to engage in a variety of activities during each class session. Through an introductory activity at the beginning of each class session the instructor presented an example of curriculum integration, lottery game, data analysis or hand-on activities in which the students participated. In small groups the students read and discussed implications and applications of the information as it related to the concepts presented by the researcher.

The instructor closely monitored each activity to assure that all students participated and accomplished the tasks to a mastery level. Extensive feedback designed to build success and promote positive attitudes was provided in all activities. Each student received approximately 90 class hours of instruction over a 16 week period of time. At the conclusion of the semester long experimental course, the researcher re-administered the Survey of Attitudes Toward Statistics (SATS) (Schau, et al. 1993) as the posttest variable. Gain scores, the difference between the pre- and posttest scores became the experimental variable for the study.

\section{METHODOLOGY}

\section{Method}

To measure the effectiveness of the semester-long on student learning, the average response to each of the 28 questions was computed at the beginning and end of the course. Each student was examined in four areas: (a) Affect- 
positive and negative feelings concerning (b) Cognitive Competency- attitudes about intellectual knowledge and skills when applied to. (c)Value - attitudes about the usefulness, relevance, and worth of statistics in personal and professional life, and (d) Difficulty-attitudes about the difficulty of statistics as a subject. The paired pretest, and posttest mean scores were calculated from four subscale and t-tests were performed at the end of the semester to determine if there were any significant changes in pre-test, posttest scores between any of the observations. To measure the effectiveness of the experiential learning project, the researcher formulated the hypothesis:

Hypothesis: The average scores on the Survey of Attitudes Toward Statistics (SATS) at the beginning and the end for the students with constructive learning environment would not be significantly different, at the $\alpha=0.01$ level.

\section{Procedure}

On the first day of class, the students were asked to volunteer to fill out the questionnaire. They were told that their participation would not affect their grade in the class, and to further assure them, they were told to use a fictitious name on the questionnaire and send it to the administrative assistant. On the second to last day of class, they were given the same questionnaire and similar instructions (including to use the same fictitious name they used on the first questionnaire).

\section{Instrument}

Participants were administered the Survey of Attitudes Toward Statistics (SATS) (Schau, et al. 1993). The SATS uses a 7 -point Likert scale $(1=$ strongly disagree, $4=$ Neither disagree nor agree, $7=$ strongly agree $)$ that contains 4 subscales: (1) Affect,(2) Cognitive Competence, (3) Value, and (4) Difficulty. Higher scores indicate more positive attitudes toward statistics. Items such as "I like statistics ", "I am under stress during statistics class ", “ Statistics is worthless", and "Most people have to learn a new way of thinking to do statistics" are example attitudinal statements from each subscale, respectively. Schau, Stevens, Dauphinee, \& Del Vecchio (1995) reported that the reliability for the subscales in SATS were Affect (alpha $=0.84$ for female, alpha $=0.81$ for male), Cognitive Competence $($ alpha $=0.83$ for female, alpha $=0.77$ for male), Value (alpha $=0.85$ for female, alpha $=0.80$ for male), Difficulty (alpha $=0.77$ for female, alpha $=0.64$ for male).

\section{Participants}

Participants in the study were undergraduate students in an introductory statistics class at a regional 4-year university in the southeastern United States. Eighty-two students were involved in this study. Out of the 82 students sampled, 2 did not complete their course.

\section{RESULT}

In order to answer research question, a t-test was used to compare the average scores on four subscales of the Survey of Attitudes Toward Statistics (SATS) performance of pretest and posttest. For the pre-questionnaire and the ending-of the-course questionnaire (Post-Questionnaire), Table 1 shows mean scores and standard deviations for the four SATS subscales and, along with the paired-sample $t$ and level of significance (2-tailed) for each subscale meandifference. As can be seen in Table 1, there was a significant $(\mathrm{p}<0.05)$ difference in pre- to post-questionnaire meanscores for each of the four subscales. The t-test results indicated that there was a statistically significant difference between the SATS mean score of the pretest and posttest, at the 0.05 significance level. Using $\alpha=0.05$ as the prestudy determined level of testing, there was sufficient evidence to reject the null hypothesis regarding differences in the measure of the average scores on the Survey of Attitudes Toward Statistics (SATS) at the beginning and the end for the students learning statistics with constructive learning approach. 
Table 1

\begin{tabular}{ccccccc}
\hline & \multicolumn{2}{c}{ Pre-Test } & \multicolumn{2}{c}{ Post-Test } & \multicolumn{2}{c}{ Post-Pre Difference } \\
& \multicolumn{2}{c}{ Scale Scores } & \multicolumn{2}{c}{ Scale Scores } & \multicolumn{2}{c}{$\begin{array}{c}\text { Scale Scores } \\
\text { Scale }\end{array}$} \\
M & SD & M & SD & \multicolumn{2}{c}{ sig(2-tailed $)$} \\
\hline Affect & 2.3 & 1.8 & 5.2 & 1.2 & 2.53 & $0.016^{*}$ \\
Cognitive & 2.9 & 2.3 & 5.7 & 1.4 & 3.07 & $0.025^{*}$ \\
Value & 3.1 & 2.1 & 5.8 & 1.2 & 3.03 & $0.024^{*}$ \\
Difficulty & 4.9 & 2.8 & 2.3 & 0.9 & 2.63 & $0.018^{*}$ \\
\hline
\end{tabular}

Table 1 shows mean scores and standard deviations for the four SATS subscales

\section{DISCUSSION}

The average student scores in the study exposed to the constructivist approach techniques had at the outset significantly more positive attitudes than the average student in the beginning section--on all of subscales. This implies that in the constructivist approach techniques students become more strongly positive attitudes towards learning statistics, which influenced their learning statistics easier.

Those who regularly teach required introductory statistics courses are well aware of the negative attitudes that many students bring to such courses. Developers of various scales to measure student attitudes have documented this in their studies (Schau, et. al., 1995; Wise, 1985). McLeod (1992), discussing the place of affect in mathematics education, has placed attitudes between beliefs and emotions in his conceptualization of the affective domain. It is likely that the same conceptualization applies to statistics. Moreover, the positive and reliable, but somewhat weak relationship between attitude towards mathematics and achievement in mathematics, found in the meta-analysis of Ma and Kishor (1997), may well also be true in statistics.

Furthermore, confidence has been shown to play a considerable role in mathematics achievement (Reyes, 1984). Moreover, related constructs, mathematical self-concept and self-efficacy, show similar relationships to achievement (Marsh, 1986; Pajares \& Miller, 1995). The extent to which students' confidence in their competence and ability contribute to their success in statistics needs to be examined more fully. Specifically, future research which attempts to examine the effects of constructivist-based learning approach should include the modeling of statistical confidence. How ever, it is possible that different ability levels among students could affect the result. Further research is needed to validate the results as well as explore factors that may be associated with this lack of relationship between involvement in individual grade and an appreciation of statistics.

\section{CONCLUSIONS}

The findings reported in this article show that students who were exposed to constructivist-based learning approach in an introductory statistics class gained positive attitudes. These results suggest that such constructivistbased learning techniques may be useful for enhancing learning. Constructivist-based learning methods may also offer alternative learning opportunities for students who do not fully grasp course material in the traditional lecture format. More nontraditional learners are opting for college study, and they are in need of more varied modes of learning (Cantor, 1995). Constructivist-based learning approach provides students with the opportunity to apply theory to reallife situations and bring concepts and theories to life, thereby enhancing student learning.

\section{REFERENCES}

1. Anderson, E. J. (1997). Active learning in the lecture hall. Journal of College Science Teaching, 26, 428-429.

2. Bradstreet, T. (1996). Teaching introductory statistics courses so that non-statisticians experience statistical reasoning. The American Statistician, 50(1), 69-78. 
3. Cantor, J. (1995). Experiential learning in higher education: Linking classroom and community. (ASHEERIC Higher Education Report No. 7). ERIC Clearinghouse on Higher Education.

4. Cobb, G. (1993). Reconsidering statistics education: A National Science Foundation conference. Journal of Statistics Education, 1(1). Retrieved May, 2003, from http://www.stat.unipig.it/ncsu/info/jse/v1n1/cobb.html

5. Dabbour, K. S. (1997). Applying active learning methods to the design of library instructions for a freshman seminar. College and Research Libraries, 58, 299-308.

6. Fillebrown, S. (1994). Using project in an elementary statistics course for non-science majors. Journal of Statistics Education, 2(2). Retrieved May, 2003, from http://www.stat.unipig.it/ncsu/info/jwe/v2n2/fillebrown.html

7. Hogg, R. V. (1991). Statistical Education: Improvements Are Badly Needed. The American Statistician, 45(4), 342-343.

8. Gal, I., Ginsburg, L., \& Schau, C. (1997). Monitoring attitudes and beliefs in statistics education. In I. Gal \& J.B. Garfield (Eds.), The assessment challenge in statistics education (pp. 37-51). Netherlands: IOS Press.

9. Garfield, J. (1993). Teaching statistics using small-group corporative learning. Journal of Statistics Education, 1,(1).Retrieved May, 2003, from: www.amstat.org/publications/jse/v1n1/garfield.html

10. Garfield, J. (1995). How students learn statistics. International Statistical Review, 63, 25-34.

11. Giesbrecht, N. (1996). Strategies for developing and delivering effective introductory-level statistics and methodology courses. Alberta, Canada. (ERIC Document Reproduction Service No. ED393 668)

12. Gordon, S. (1995). A theoretical approach to understanding learners of statistics. Journal of Statistics Education, 3(3). Retrieved May, 2003, from http://www.stat.unipig.it/ncsu/info/jse/vene/gordon.html

13. Lewis, L. H. \& Williams, C. J. (1994). Experiential learning: Past and present. In L. Jackson \& R. S. Caffarella (Eds.), Experiential learning: A new approach (pp. 5-16). San Francisco: Jossey-Bass.

14. Ma, X. \& Kishor, N. (1997). Assessing the relationship between attitude toward mathematics and achievement in mathematics: A meta-analysis. Journal for Research in Mathematics Education, 28, 26-47.

15. Marsh, H. W. (1986). Verbal and math self-concepts: An internal/external flame of reference model. American Educational Research Journal, 23, 129-149.

16. McLeod, D. B. (1992). Research on affect in mathematics education: A re-conceptualization. In D.A. Grouws (Ed.), Handbook of Research on Mathematics Teaching and Learning (pp. 575-596). New York: Macmillan Publishing Company.

17. Moore, D. S. (1997) New pedagogy and new content: the case of statistics, International Statistical Review, 65, 123-137.

18. Pajares, F. \& Miller, M. D. (1995). Mathematics self-efficacy and mathematics performances: The need for specificity of assessment. Journal of Counseling Psychology, 42, 190-198.

19. Reyes, L. H. (1984). Affective variables and mathematics education. Elementary School Journal, 84, 558581.

20. Schau, C., Dauphinee, T. L., \& Del Vecchio, A. (1993). Evaluation of two surveys measuring students attitudes toward statistics. Paper presented at the annual meeting of the American Educational Research Association, Atlanta, GA.

21. Schau, C., Stevens, J., Dauphine, T. L., \& Del Vecchio, A. (1995). The development and validation of the Survey of Attitudes Towards Statistics. Educational and Psychological Measurement, 55, 868-875.

22. Schutz, P. A., Drogosz, L. M., White, V. E., \& Distefano, C. (1998). Prior knowledge, attitude, and strategy use in an introduction to statistics course. Learning and Individual Differences, 10, 291-308.

23. Shakarian, D. C. (1995). Beyond lecture: Active learning strategies that work. Journal of Physical Education, Recreation, and Dance, 66, (May/June), 21-24.

24. Vellerman, P. F. \& Moore D. S. (1996). Multimedia for teaching statistics: Promises and pitfalls. The American Statistician, 50, 217-225.

25. Wise, S. L. (1985). The development and validation of a scale measuring attitudes towards statistics. Educational and Psychological Measurement, 45, 401-405. 
NOTES 